This is the peer reviewed version of the following article:

Cameron, A., Brangan, E., Gabbay, J., Klein, J., Pope, C., \& Wye, L. (2017). 'Discourses of joint commissioning'. Health and Social Care in the Community. DOI: $10.1111 /$ hsc.12462

which has been published in final form at http://dx.doi.org/10.1111/hsc.12462.

This article may be used for non-commercial purposes in accordance with Wiley Terms and Conditions for Self-Archiving. 


\section{Discourses of Joint Commissioning}

\section{Abstract}

Increasing attention has focused on the role of joint commissioning in health and social care policy and practice in England. This paper provides an empirical examination of the three discourses of joint commissioning developed from an interpretative analysis of documents by Dickinson et al (2013) and applied to data from our study exploring the role of knowledge in commissioning in England. Based on interviews with 92 participants undertaken between 2011 and 2013 our analysis confirms that the three discourses of prevention or empowerment or efficiency are used by professionals from across health and social care organisations to frame their experiences of joint commissioning. However, contrary to Dickinson et al, we also demonstrate that commissioners and other stakeholders combine and trade off these different discourses in unexpected ways. Moreover, at sites where the service user experience was central to the commissioning process (joint commissioning as empowerment) a greater sense of agreement about commissioning decisions appeared to have been established even when the other discourses were also in play.

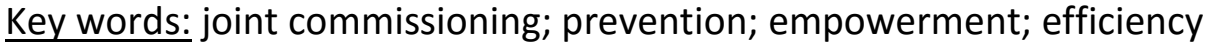

\section{What is known about the topic.}

- Reforms of the health and social care sector have focused greater attention on the role of commissioning.

- Commissioning is a messy process, made more complex when commissioning in tandem with other agencies.

- Three discourses of joint commissioning: prevention; empowerment and efficiency have previously been identified in an interpretative analysis of government documents.

What this paper adds.

- Commissioners use these discourses when talking about joint commissioning in practice, often combining them to justify decisions made. 
- The empowerment discourse, in which services are developed to reflect the needs of those using them, appears to play a particularly prominent role in supporting and legitimating joint commissioning decisions.

\section{$\underline{\text { Introduction }}$}

Much attention has focused on the role of joint working as a means to improve the provision of services both within and across sectors, particularly between health and social care organisations (Goodwin 20013, Coleman et al 2014). In England interest has focused on developments at both operational and strategic levels, including the role of commissioning. Indeed, as the marketization of services has proceeded, commissioning has become an important feature of policy and practice, with joint commissioning a key activity for many health and social care agencies.

Commissioning is the process by which an organisation makes decisions about 'needs assessment, resource allocation, service purchasing, monitoring and review' (Smith et al 2010). Clinical Commissioning Groups (CCGs) are the clinically-led statutory bodies who commission mental health services, urgent and emergency care, elective hospital services, and community health care. There are 209 CCGs in England and together they are responsible for some $2 / 3$ of the total NHS England budget. Local Authorities are responsible for a range of social care services and public health, such as commissioning personal care services for the housebound elderly and identifying the health care needs of the local population through the annual 'joint strategic needs assessment' process. Joint commissioning was introduced to support the development of integrated services in the community, based around the needs of local people, by working across the NHS and Local Authority interface. Joint commissioning refers to the process by which partners, in this case from CCGs and local authorities, work together to set out a vision for local commissioning (Humphries and Wenzel 2015) in a way that makes the best use of limited resources in the design and delivery of services and improve outcomes' (Dickinson et al 2012:1). In this context jointly commissioned services could include: falls prevention; intermediate care and, multidisciplinary community mental health teams. 
This paper reports findings about the nature of joint commissioning that were derived from a National Institute for Health Research, Health Service Delivery Research (NIHR HSDR) funded study (published elsewhere authors 2014, 2015a, 2015b) of the use of external organisations that provide knowledge and information to commissioners to support decision making in the National Health Service (NHS) in England. The article begins with a brief overview of recent developments in joint working and commissioning.

\section{Developments in joint working and commissioning}

The importance of health and social care agencies working together is well established, both in England and internationally (Wodchis et al 2015). Not only is joint working thought to improve the experience of people who use services, ensuring that services are co-ordinated to meet their needs but it is also considered important as a means to promote more efficient and effective services, a requirement for governments, particularly in the light of current cuts in public spending.

Whilst attempting to improve joint working, successive governments in England have pursued a range of mechanisms, focusing both on strategic initiatives to encourage the NHS and its local authority partners to collaborate in the planning and financing, as well as in the delivery of health and social care services (Author 2016). Such initiatives became more pressing during the 1980s and 1990s as a consequence of the Conservative government's efforts to 'marketize' public services. These reforms included the establishment in the NHS of the 'internal market' or 'purchaser-provider split' and its later introduction in social care. More recent initiatives to extend the role of the market have seen the separation of commissioning and provider functions within community health services through the creation of CCGs to replace PCTs that were responsible for commissioning healthcare. As a consequence of these changes greater attention has fallen on the role of commissioning. The Health and Social Care Act 2012, for example, saw the establishment of Health and Wellbeing Boards (HWBs) as a means to bring together locally elected councillors with commissioners of services from the NHS and local government. HWBs are expected to lead the assessment of local needs, providing evidence to inform joint commissioning whilst at the same time improving the democratic legitimacy of decision making (Coleman et al 
2014:562). The Better Care Fund introduced to support transformation and integration of health and social care services $(\mathrm{DH}, 2013)$ attempted to stimulate joint commissioning with respect to services for older people. Recent government pronouncements have suggested co-commissioning (DH 2014) as a means to reduce barriers between care providers by joining up their commissioning (Greener 2015), as well as providing a mechanism that guards against 'conflicts of interest' (Checkland et al 2016:7).

In recent years the landscape has become more receptive to external commercial and noncommercial provision in the NHS. Indeed the Health and Social Care Act 2012 is founded on a belief that 'individual creativity and innovation is best supported by competition' (Lansley 2012). The underlying assumption is that competition amongst providers will encourage the development of innovative services which, in turn, will better meet the needs of service users. However, there is limited evidence that the application of market principles enhances the quality of services or reduces costs (Dickinson et al 2012).

\section{Understanding Commissioning and Joint Commissioning}

While there are many definitions of 'commissioning' (Newman et al 2012) the Department of Health has issued guidance elaborating such prerequisites as assessing needs, designing services and managing demand and performance. Such guidance belies the complexity of commissioning, a 'messy' activity (Checkland et al 2011) which involves 'juggling competing agendas, priorities, power relationships, demands and personal inclinations to build a persuasive, compelling case' (Authors 2015b).

The suggestion that different agencies should collaborate in this endeavour implies an even greater level of complication. While researchers have focused on the practical barriers facing those engaged with collaborative commissioning (Coleman et al 2014, Baxter et al 2007) as well as the potential role of the public in commissioning (Glasby et al 2010), efforts to understand the process have not featured as extensively. However, an interpretative analysis of key documents relating to joint commissioning provides useful insights to the different discourses used to frame the activity (Dickinson et al 2013). The study set out to explore the outcomes envisaged for joint commissioning and identified three discourses framing joint commissioning as: 
- prevention, a mechanism to improve service delivery and hence reduce inequalities;

- empowerment, thereby ensuring that services are developed to reflect the needs of those using them and,

- efficiency, suggesting a link between the improvement of performance and the elimination of duplicate services.

This paper sets out to analyse data collected in our study in the light of these discourses to explore their usefulness in explaining people's experiences and perceptions of joint commissioning.

\section{METHODS}

\section{Study design}

The data reported in this paper derives from a broader study of commissioning practice, which adopted a mixed-method case-study approach. This approach is particularly well suited to exploring complex phenomena where researchers have no control over the settings or events they wish to study (Yin 2013).

\section{Case site selection and access}

Four commissioning organisations, which at the time of the study were in different stages of transforming from PCTs into Clinical Commissioning Groups CCGs, were approached to take part in the study. Once the commissioning organisations had agreed to take part formal applications were made through research governance. Ethical review was received from South West Ethics Committee 2 (10/H0206/52).

\section{Data collection}

Fieldwork took place between February 2011 and May 2013, nine months after the publication of Liberating the NHS, the White Paper that led to the 2012 Health and Social Care Act. The study combined the use of semi-structured interviews, observation and documentary analysis. This paper, however, draws solely on analysis of interview data.

Topic guides for the interviews were developed in order to elicit information about the nature of the commissioning process as well as the types of knowledge sought by 
commissioners, information sources and how it influenced decisions. By the nature of the interviews, discussions often extended to the challenges faced by commissioners, including those related to joint commissioning which, at the time of the research, were increasingly significant. Participants were interviewed in person or by telephone, depending on the preference of the participant and practicalities. The interviews lasted between 20 and 60 minutes and were recorded and transcribed in full by an external transcriber.

In total, we interviewed 92 participants including 47 from the NHS, 36 external consultants and nine others (including representatives from public health, local authorities, freelance consultants and a lay representative). Several of the NHS participants had previous experience of working within local government and were able to offer insights based on this perspective.

\section{Data analysis}

The data were analysed using inductive and deductive processes (Fereday and MuirCochrane 2006). Preliminary analyses were inductive, using constant comparison to identify codes. During the course of the fieldwork the research team met regularly to identify emerging themes, reflect on the research questions and suggest new questions for the fieldwork. When the fieldwork finished three members of the team (initials) developed a coding frame based on these previous discussions. These themes were applied to the full data set using NVIVO. In addition two members of the team (initials) then developed case summaries for each of the cases. These summaries were structured around five domains: four of which originated from the original research questions (external providers, knowledge accessed, knowledge transformation, benefits/disadvantages) while the final domain (models of commissioning) emerged inductively from the analysis. All members of the research team read these summaries and conducted cross-case analyses, identifying common themes. The team then met to confirm the key themes (Authors 2015b).

The main study aimed to identify different models of commissioning in order to explore how external providers of knowledge are used within these models, discussed below. A subsequent analysis was undertaken of those interviews where joint commissioning had featured. This element focused on exploring whether the different discourses of joint 
commissioning were present in the data and how they were framed. This analysis was led by one member of the team (initials) and confirmed with the PI (initials) and research fellow (initials).

This paper focuses on joint commissioning. Data are presented from three examples of joint commissioning. We use Dickinson et al's (2013) discourses of joint commissioning to explore the ways in which participants discussed local commissioning arrangements, including how information was used to support these processes. The challenges of joint commissioning are also discussed.

\section{Findings}

\section{Models of commissioning}

Analysis of the data identified three models of commissioning: commissioning of clinical services by the CCG; commissioning conducted by a commercial organisation and finally the integrated health and social care commissioning model, otherwise known as joint commissioning (Authors et al 2015b), which forms the focus of this paper.

Experiences of joint commissioning were discussed at three of our four sites, labelled here as follows:

- 'Carnford' CCG - struggling financially, highly collaborative with its healthcare providers;

- 'Deanshire' CCG - a confident commissioning organisation;

- 'Penborough' CCG - an integrated network of health and social care provision with an emphasis on public involvement.

For the purposes of anonymization participants have been assigned a pseudonym.

\section{Discourses of joint commissioning}

This paper seeks to test the discourses of joint commissioning developed by Dickinson et al against the experiences and perspectives that we found among professionals involved in practice. 
We were able to identify examples of each of the three discourses of joint commissioning identified by Dickenson et al: prevention; empowerment; and efficiency. The use of joint commissioning as a mechanism to deliver care earlier, which is what Dickinson et al refer to as a discourse of prevention, was mobilised by participants from all three sites. For example Lynn, a GP and vice chair of CCG clinical operations group from Deanshire, described the function of a recently commissioned joint health and social care team (reablement service) as being to "accept referrals from not only the practice [General Practice] but from the acute trusts [hospital], and the premise is really that you ... you put a lot more input into a patient's health right at the beginning, so as soon as they start wobbling or start, you know if they've had one fall you get someone in there straightaway, so you try and be a lot more proactive about their care. You give them quite a lot more intensive input for the first six weeks with a view that actually, that will save in the longer term." This example clearly fits with a narrative of prevention, echoing many of the themes of the 2014 Care Act, including the promotion of wellbeing by the use of preventive services and improving care and support planning through the establishment of an integrated team.

This prevention-based discourse was also used in combination with an efficiency discourse, suggesting prevention can lead to reduced costs. For example Roger, a GP involved in commissioning in Carnford, described how they were using information to inform commissioning decisions by trying "to focus care on those who are going to run up high costs, to try to reduce those costs. Because, I mean, the theory goes that if you can predict those individuals and you can intervene to improve their care, and stop inappropriate care happening, so this would be particularly making sure that people are well supported in the community and so they don't suddenly run into problems and get admitted to hospital inappropriately." Similarly, Alan the service lead for unplanned care at Penborough, described how integrated services for people with long term conditions could help meet the needs of "high users", "which tend to be people with two, three, four long-term conditions. And no surprise, you get to a certain point on the graph and 5\% of your people like that are spending half your money. So it's right to focus on them, and try and obviously make best use of your resources, but also improve their outcomes." 
In looking at the prevention-based discourse further, Dickinson et al suggest that Joint Strategic Needs Assessment (JSNAs) can play a supportive role in informing commissioning decisions that have a preventative function. JSNA documents set out the health and wellbeing of a local community and as such inform the joint commissioning process. Only 7 out of the 38 participants across the 3 sites mentioned JSNAs. Generally JSNAs were regarded as a source of information to help prioritise commissioning decisions. Abbie, the CCG director of clinical commissioning development from Deanshire, regarded JSNAs as providing "a really good understanding of what their local needs are and the areas that they should be looking at, which is really helpful." In this sense JSNAs informed the preventative commissioning agenda.

The second discourse identified by Dickinson et al, that of empowerment, was defined as an opportunity to 'focus on meeting the needs of service users and carers through the coproduction of their own care' (Dickinson et al 2013:6). This discourse was most evident in the interviews at Deanshire. In preparation for the establishment of a re-enablement service, health and social care partners had undertaken a 'listening exercise' with a small number of patients to understand their experiences of services. This exercise revealed that patients were frustrated, as Abbie the CCG director of clinical commissioning described: "... what we discovered was that actually lots of people did lots of things but nobody actually stopped to listen to find out what the real problem was". With this in mind, commissioners decided to initiate a new approach founded on a set of values that put the patient at the heart of the process. Jane, a commissioner with a background as an OT, described how commissioners are "so caught up with the contracts and the performance and so on, I think we sometimes lose sight of, what was it that this services is actually intending to do in the first place?" As a result "some of the projects we've done lately we've very much built services around what the patients have told us." Lynn, the vice chair of the CCG clinical operations group, described how the aim was to move away from having a set package of services to support people in the community to having a more personalised response that recognises "what the real problem is and what the patient wants to achieve." Commissioning across organisational boundaries made this aim more achievable. 
Other participants from Deanshire used the discourse of empowerment with regard to commissioning. Felicity who worked for a private consultancy, although she had previously worked for the council, described how traditional approaches to commissioning had led to the wrong outcome. She described how in her view "the commissioning logic has led to price-led, service-shaped solutions, and not necessarily what people need in order to help them. Having decided to develop an approach to commissioning with the patient at the heart, by necessity commissioners need to develop more flexible relationships with providers based on mutuality and co-operation". She went on to argue that what they had learnt from a listening initiative in Deanshire was that "if you solve a person's problem having person-shaped solutions, then overall you spend less, because that person is not then either becoming dependent upon the solution that you've predetermined for them, because if you're commissioning standardised solutions then what you'll get is solutions that go over and under need, but rarely meet need." Personalised commissioning, for example through mechanisms such as Personal Budgets, which enable individuals to make choices about what support they want to receive, was difficult for commissioners to adjust to because it challenged the traditional process of commissioning "in bulk" and was thought to necessitate "a very different commissioning conversation with the providers of services." Clearly this approach was perceived to offer a more personalised service response for individuals, a key operational feature of Dickinson et al's empowerment discourse but participants also implie that personalisation can lead to cost savings. However, the inherent contradiction between such person centred approaches and the need to reduce expenditure was not considered by participants (Slasberg and Beresford 2016).

Whilst the move towards a more 'empowering' view of commissioning was driven by a decision to put patients at the heart of the process, participants recognised that there were other motives for this approach, particularly to achieve greater efficiencies. As Jane, a commissioner from Deanshire, reported "it felt we seemed to spend so much time lately trying to save the money, trying to make things more efficient and more effective, and taking it from the wrong end of the pathway .... Whereas if we actually did the right thing for the patient first, then we find we get those outcomes as a secondary consequence." In this sense, Jane's statement suggests that efficiency and empowerment are easily intertwined. 
The empowerment discourse was also alluded to in interviews with professionals at the other sites. For example Carol, the deputy chief executive at Penborough which operated an integrated adult social care and health commissioning model, noted a range of ways in which the public were involved in joint commissioning decisions, including a community forum established to encourage public engagement in debate. Additionally, the organisation had chosen to involve individual patients in focused reviews of services, alongside a clinical lead and service manager. Lorraine, who worked for the CCG, described how lay involvement in a recent review of unscheduled care had helped ensure that they had an "understanding of what's happening in a local community, what the needs of the local community are, so they're looking at the pathways, how that's going to work." She went on to describe how these reviews were crucial to commissioning decisions, "so they're establishing, in a sense, what we want to commission and how we want things to change." While the empowerment discourse was not as prevalent at Carnford its potential was noted by Anthony, a GP and chair of the unscheduled care board. He noted that public involvement in decision making wasn't "just about having the public involved in pathway design or care design [having] lay people communicating messages could be very powerful alongside clinicians or board members or politicians or whatever."

The final discourse identified by Dickinson et al locates joint commissioning in the context of improving the efficiency of services, for example by reducing duplication. But they also suggest that by increasing the number of service providers, commissioners will benefit from the competition amongst them to win contracts. Dickinson et al (2013:6) argue that central to this discourse is the relationship between commissioners and 'providers of care and how these are contracted with and performance managed.' For example George, the director of integrated commissioning from Penborough, who had previously been a deputy director of social services, described how an integrated commissioning strategy helped them respond to whole population needs while at the same time they were able to "flex the resources and the money much easier, and to get the benefit from being able to do that." George went on to describe how commissioners needed to ensure the care system was functioning properly and was "competitive where it needed to be." He went on to describe the importance of having a clear understanding of "the emerging architecture you need to have to get to those objectives [for example] shifts of resources, the redesign of the balance 
in the models of care, the way the private long-term care and home care sectors needs to play more of a role in relation to keeping complex needs at home." Similarly Lorraine, who was the deputy chief finance officer at the CCG, described how financial pressures in the system led to providers being put under pressure "to drive out their efficiency savings. So it's how we can work with them to do things in a different way so they're still financially sustainable while maintaining quality services."

There were other examples of the discourse of joint commissioning as efficiency at each site. At Carnford Connie, an information analyst, said the decision to develop an integrated service was taken in order to resolve problems associated with delayed discharges "where social services aren't ready to accept that person discharged back into their care yet"; similar problems were experienced by people who were discharged too early who then "go out to social services, something goes wrong, and they ping back out and they'll be back again." At Deanshire a management consultant from one of the external organisation described initiatives to talk with service users about their experiences of services. These discussions had helped commissioners identify " $a$ hell of a lot of overlap, and they were just unaware of that," suggesting once more that by listening and empowering service users to talk about their experiences commissioners were able to identify unnecessary expense, in this case duplication of services between providers.

\section{Discussion}

This study did not originally set out to focus on joint commissioning. However, during our interviews exploring the use of external providers of knowledge some participants drew on their experiences of joint commissioning to describe the challenges and opportunities they faced. This paper applies Dickinson et al's 2013 framework of three discourses of joint commissioning, which was originally derived from an interpretative analysis of key government documents, to explore how those involved in the real world of joint commissioning frame the practice.

While Dickinson et al suggest that the three distinct discourses they observed in the literature 'may not comfortably co-exist in practice' (2013:8), our analysis demonstrates that they do. Participants often marshalled more than one of these discourses within one 
interview. Moreover, while Dickinson et al suggest there might be tensions between these discourses our analysis suggests that participants also combined them as a means to build a persuasive argument to support a commissioning decision (Authors 2015b). For example, when participants framed joint working in relation to preventative services they often linked this to the need to make services more efficient and hence save money, a pressing objective given the financial pressures on both the NHS and local authorities. The same is true of much of the data that frames joint commissioning as the empowerment of patients and service users. This blend of discourses should not be unexpected. Given the emphasis given to each of these discourses in current policy and practice, most notably in the 2014 Care Act, and wider public discourses, it is probably inevitable that participants use multiple discourses to frame the 'messy' world of joint commissioning. The art of commissioning requires multiple discourses with people and organisations that have conflicting needs and values. For example, while health or social care commissioners may need to appeal to the empowerment discourse in order to minimise local political criticism, or a preventative discourse to persuade clinicians, it would be hard to imagine them not mobilising an efficiency discourse when justifying a decision to the managers of the budget. However, whether joint commissioning can deliver efficiency savings on the scale imagined is an untested assumption. Although the authors of a synthesis of the research evidence in 2012 suggest that joint commissioning may lead to savings, for example in administration and transaction costs, they note that the evidence base is not extensive and was of low quality (Newman et al 2012).

It is interesting to note that in two of the three sites where examples of joint commissioning were discussed in detail, the knowledge that was privileged to support commissioning decisions was that derived from service users. This finding appears to support Dickinson et al's suggestion that one discourse is likely to prevail, but not, however, to the exclusion of others. In the reablement project in Deanshire, service users were the reference point in understanding what worked (and what did not) and their perspectives were gathered in a range of ways including through consultations and shadowing. Additionally at Penborough, the expertise of users of services was instilled into commissioning through their involvement as strategic leads, elected councillors as Board members and through a community forum. In other words, the voice of service users was centre stage and appeared to coalesce 
commissioning activities across the constituent organisations. Participants from both sites, however, also used other discourses, including efficiency but were arguably legitimating their decisions by couching them in more than just a rigid discourse of efficiency. Perhaps this interpretation of the importance given to service user experiences in commissioning decisions reflects a wider sense in which the concept of 'public engagement' has now been adopted by health and social care policy and practice (Hudson 2015). Indeed, the data suggests that those sites that had put the service user experience at the heart of the commissioning process, joint commissioning as empowerment, appeared to have achieved a greater sense of purpose and agreement about what they were trying to accomplish. However, a more cynical interpretation of this finding, might suggest that by accentuating the discourse of empowerment, professionals found it easier to justify contentious decisions. Alternatively, as relatively senior representatives within their organisations, the emphasis they gave to the 'empowerment' of service users might merely be a nod to a dominant contemporary discourse, one which they expected the researchers to be familiar with and perhaps expect to hear.

\section{Strengths and limitations}

The originality of this paper lies in its application of three discourses of joint commissioning, developed from an interpretative analysis of documents, to data collected in a large scale empirical study of commissioning practice in England. However, given the broader nature of the originating empirical study it is possible that participants provided only a partial picture of local experience. Additionally, given current levels of interest in commissioning it is possible that participants were inclined to provide more 'positive' accounts of these practices.

\section{Conclusion}

Joint commissioning is an increasingly important activity within health and social care in England. In this paper, we have examined Dickinson et al's three discourses of joint commissioning to explore the reality of commissioning from perspectives of those involved in the activity. Our findings suggest that the three discourses of prevention, empowerment and efficiency are often mobilised in combination rather than in isolation, perhaps reflecting 
not only current policy and practice debates but also the inevitable multiple pressures and tensions that shape commissioning decisions, especially in times of austerity. However, the empowerment discourse may play a particularly prominent role in supporting and legitimating joint commissioning decisions. The involvement of service users in joint commissioning activities was reported to be a powerful tool, in terms both of refocusing commissioning decisions away from traditional 'one size fits all' services and offering a discourse that legitimates controversial decisions. 


\section{$\underline{\text { References }}$}

Authors (2014) report

Authors (2015a)

Authors (2015b)

Author (2016)

Baxter, K., Weiss, M., Le Grand, J. (2007) Collaborative Commissioning of Secondary Care Services by Primary Care Trusts. Public Money \& Management 27(3) 207-214.

Checkland, K., Snow, S., McDermott, I., Harrison, S., Coleman, A. (2011) Management practice in primary care organisations: the roles and behaviours of middle managers and GPs: Final report. NIHR Service Delivery and Organisation Programme.

Checkland, K., McDermott, I., Coleman, A., Perkins, N. (2016) Complexity in the new NHS: longitudinal case studies of CCGs in England. BMJ doi:10.1136/bmjopen-2015-010199

Coleman, A., Checkland, K., Segar, J., McDermott, I., Harrison, S., Peckham, S. (2014) Joining it up? Health and Wellbeing Boards in English Local Governance: Evidence from Clinical Commissioning Groups and Shadow Health and Wellbeing Boards. Local Government Studies 40(4)560-580.

Department of Health. (2007a) World Class Commissioning. London: Department of Health.

Department of Health. (2010) Liberating the NHS. London: Department of Health.

Department of Health. (2012) Health and Social Care Act. London: Department of Health.

Department of Health (2013) Integrated Care and Support: Our Shared Commitment. London: Department of Health.

Department of Health. (2014) Next steps towards primary care co-commissioning. London: Department of Health.

Dickinson, H., Glasby, J., Nicholds, A., Sullivan, H. (2013) Making sense of joint commissioning: three discourses of prevention, empowerment and efficiency. BMC Health Services Research, 13 (suppl 1).

Dickinson H, Shaw, S., Glasby J, Smith, J. (2012). The limits of market-based reforms. BMC Health Services Research 13 (supp 1).

Fereday, J., Muir-Cochrane, E. (2006) Demonstrating Rigor Using Thematic Analysis: A Hybrid Approach of Inductive and Deductive Coding and Theme Development. International Journal of Qualitative Methods 5(1)(83).

Glasby, J., Dickinson, H., Smith, J. (2010) 'Creating NHS Local': The Relationship between English Local Government and the National Health Service. Social Policy \& Administration 44(3)244264. 
Goodwin, N. (2013) Understanding integrated care: a complex process, a fundamental principle. International Journal of Integrated Care. Jan-Mar: 1-2

Greener, M. (2015) Co-commissioning: the architecture of integration. Practical Diabetes. 32(1)10-11.

Hudson, B. (2015) Public and Patient Engagement in Commissioning in the English NHS: An idea whose time has come? Public Management Review. 17(1)1-16.

Humphries, R., Wenzel, L. (2015) Options for integrated commissioning: beyond Barker. London: King's Fund.

Lansley A. (2012) Andrew Lansley: competition is critical for NHS reform. Health Service Journal 13 February 2012.

Newman M., Bangpan M, Kalra N, Mays N, Kwan I, Roberts T. (2012) Commissioning in health, education and social care Models, research bibliography and in-depth review of joint commissioning between health and social care agencies. London: EPPI Centre Institute of Education University of London.

Slasberg, S., Beresford, P. (2016) The eligibility question - the real source of depersonalisation? Disability \& Society 31(7)969-973.

Smith, J., Curry, N., Mays, N., Dixon, J. (2010) Where next for commissioning in the English NHS? Nuffield Trust.

Smith, J., Porter, A., Shaw, S., Rosen, R., Blunt, I., Mays, N. (2013) Commissioning high quality care for people with long term conditions. Nuffield Trust.

Yin R. (2013) Case Study Research. London: Sage

Wodchis, W.P., Dixon, A., Anderson, G.M., Goodwin, N. (2015) Integrating care for older people with complex needs: key insights and lessons from a seven-country cross-case analysis. International Journal of Integrated Care. 15: 23 September 